\title{
Low-dose radiation, scientific scrutiny, and requirements for demonstrating effects
}

\author{
Anders Pape Møller ${ }^{1 *}$ and Timothy Alexander Mousseau ${ }^{2}$
}

\begin{abstract}
Recent nuclear accidents have prompted renewed interest in the fitness consequences of low-dose radiation. Hiyama et al. provided information on such effects in the Japanese pale grass blue butterfly in a paper that has been viewed more than 300,000 times, prompting a barrage of criticism. These exchanges highlight the role of scrutiny in studies with potential effects on humans, but also raise questions about minimum requirements for demonstrating biological effects.
\end{abstract}

Natural background radiation varies by more than a factor of 300 with significant negative effects on mutation, immunology and disease [1]. Low-dose radiation has been known to have negative consequences for living beings for almost 100 years [2]. Indeed, background radiation causes the death of tens of thousands of humans annually [3]. These 'natural' effects may be exacerbated by the 23 nuclear accidents recorded during the last century, ranging from 4 to 7 on the International Nuclear Event Scale [4]. A level 4 accident is defined as having local consequences involving a release of radioactive materials exceeding $0.1 \%$ of core inventory with a high probability of significant public exposure and at least one death from radiation. Only Chernobyl and Fukushima have reached the highest level of 7 for a core meltdown with a major release of radioactive materials and predicted widespread health and environmental impacts, although another major nuclear accident is predicted to occur during the next 50 years [4]. Hence it is not surprising that there is a renewed proactive interest in the consequences of low-dose radiation on all organisms, including humans, under field conditions.

\footnotetext{
* Correspondence: anders.moller@u-psud.fr

'Laboratoire d'Ecologie, Systématique et Evolution, CNRS UMR 8079,

Université Paris-Sud, Bâtiment 362, F-91405, Orsay Cedex, France

Full list of author information is available at the end of the article
}

Surprisingly, the health consequences of nuclear accidents are poorly understood [5]. For example, the range of estimated excess human deaths due to the Chernobyl accident varies from less than 50 [6] to several hundred thousand [7], with scientists associated with the nuclear industry and governmental oversight bodies consistently reporting low estimates and 'independent' scientists generally providing larger estimates. Recently, Hiyama et al. [8] presented the most extensive information so far on abnormalities and survivorship caused by chronic lowdose radiation in any species, in this case the pale grass blue butterfly Zizeeria maha under field conditions in Japan.

\section{Levels of scientific scrutiny}

The paper by Hiyama et al. [8] has been viewed a staggering 302,400 times as of 24 July 2013. The main findings across ten localities that included Fukushima were elevated frequencies of morphological abnormalities in butterflies from Fukushima, a higher frequency of abnormalities in the second and the third generation compared to the first, which was not exposed to radiation, and an increase in abnormalities for butterflies treated with internal and external radiation exposure under laboratory conditions (Table 1). Interestingly, elevated frequencies of abnormalities were associated with smaller size and depressed survival rates as expected for deleterious mutation. Minor morphological abnormalities are well known to increase in frequency under environmental stress, including exposure to radiation, as is the link between abnormalities and elevated risk of death [9].

The approaches adopted by Hiyama et al., the sample sizes, and the analyses are standard for ecological and evolutionary studies, so there is no major reason for objections. Still, numerous objections were raised to these interesting findings. In a rebuttal Hiyama et al. [10] provided extensive evidence that supports their initial conclusions (Table 2). In particular, they have shown five important findings: the color patterns obtained in 
Table 1 Predictions and statistical tests for effects of low-dose radiation on pale grass blue butterflies (Hiyama et al. [8])

\begin{tabular}{lll}
\hline Analyses & Expectations & Findings \\
\hline $\begin{array}{l}\text { Spatial } \\
\text { variation }\end{array}$ & $\begin{array}{l}\text { If radiation was the causative agent, we should expect more abnormalities in samples } \\
\text { from Fukushima }\end{array}$ & $\begin{array}{l}\text { Increased frequency of abnormalities at } \\
\text { Fukushima }\end{array}$ \\
$\begin{array}{l}\text { Temporal } \\
\text { variation }\end{array}$ & $\begin{array}{l}\text { If radiation was the causative agent, we should expect fewer abnormalities in samples } \\
\text { from the first generation not exposed to radiation compared to second and third } \\
\text { generations }\end{array}$ & $\begin{array}{l}\text { Increased frequency of abnormalities in } \\
\text { second and third generations }\end{array}$ \\
$\begin{array}{l}\text { Radiation } \\
\text { experiment }\end{array}$ & $\begin{array}{l}\text { If radiation was the causative agent, we should expect more abnormalities in animals } \\
\text { exposed to internal and external radiation in the lab }\end{array}$ & $\begin{array}{l}\text { Increased frequency of abnormalities } \\
\text { following lab exposure to radiation, but } \\
\text { not in controls }\end{array}$ \\
Survival rate & If radiation had negative effects, we should expect delayed growth and reduced survival & $\begin{array}{l}\text { Reduced growth and survival in } \\
\text { irradiated samples }\end{array}$ \\
\hline
\end{tabular}

Fukushima differed from color patterns produced by aberrant temperatures and sibling crosses; the minor morphological abnormalities were not present at high frequency in Fukushima before the accident, as shown by older specimens in collections; the abnormal traits were heritable; mutation accumulation occurred from May to September 2011; and finally, positive controls produced normal adults. These findings and approaches are well within expectations for rigorous scientific research.

But the great strength of this study rests with the use of lab-based experimental manipulations of radiation that capture the genetic and phenotypic consequences observed in the wild-caught populations. In the absence of such experimental manipulations this study would be far less convincing given the small sample sizes of field collections, and lack of replication of populations within contaminated areas with the result that a dose-response relationship could not be characterized for wild populations. However, the use of experimental manipulations provides unambiguous support for the hypothesis that radioactive fallout is the likely cause of the abnormalities observed in the field and this effectively counters all of the major criticisms that have been levied at this study.

\section{Minimum requirements for demonstrating low- dose effects}

The papers by Hiyama et al. $[8,10]$ raise questions about the minimum levels of scientific scrutiny for demonstrating effects of low-dose radiation, but also other environmental health problems. We consider the approach taken by Hiyama et al. $[8,10]$ to be fully adequate for an initial investigation of association between radiation, mutations, and their phenotypic effects. However, the following additional research questions should be addressed (Table 3). First, numerous ecological phenomena are density-dependent, and that is also the case for minor morphological abnormalities [9]. Given the increased levels of mortality in contaminated areas, we consider the frequency of abnormalities in contaminated areas are likely to be under-estimates. Larger scale sampling of populations would likely address this issue. Second, because animals are smaller and have more abnormalities in contaminated areas, they might be more likely to be caught. Characterization of capture efficiency could help to address this question. Third, whole-genome sequencing of butterflies from specimens irradiated in the laboratory and collected from control areas and the first, second and third generations in

Table 2 Predictions and statistical tests for effects of low-dose radiation on pale grass blue butterflies (Hiyama et al. [10])

\begin{tabular}{|c|c|c|}
\hline Analyses & Expectations & Findings \\
\hline $\begin{array}{l}\text { Color patterns specific } \\
\text { for radiation }\end{array}$ & $\begin{array}{l}\text { If radiation is a unique environmental stressor, we should expect } \\
\text { specific effects of radiation }\end{array}$ & $\begin{array}{l}\text { Color patterns were specific for radiation, and differed } \\
\text { from those caused by temperature and crosses } \\
\text { between siblings }\end{array}$ \\
\hline $\begin{array}{l}\text { Temporal variation } \\
\text { predating the accident }\end{array}$ & $\begin{array}{l}\text { If radiation is the causative agent for abnormalities, there should } \\
\text { be fewer abnormalities from Fukushima before the accident }\end{array}$ & $\begin{array}{l}\text { Lower frequency of abnormalities at Fukushima before } \\
\text { than after the accident }\end{array}$ \\
\hline $\begin{array}{l}\text { Heritability of minor } \\
\text { morphological } \\
\text { abnormalities }\end{array}$ & $\begin{array}{l}\text { If the abnormalities are caused by germline mutations, we should } \\
\text { expect these to be transferred to the next generation }\end{array}$ & $\begin{array}{l}\text { Offspring resembled their parents with respect to } \\
\text { abnormalities in random crosses }\end{array}$ \\
\hline Mutation accumulation & $\begin{array}{l}\text { If mutations accumulate over time, there should be an increase in } \\
\text { the frequency of abnormalities from first over second to third } \\
\text { generation }\end{array}$ & $\begin{array}{l}\text { Increase in frequency of abnormalities across } \\
\text { generations }\end{array}$ \\
\hline Positive controls & $\begin{array}{l}\text { Controls reared in the laboratory, but not exposed to radiation } \\
\text { should resemble animals from control areas with respect to } \\
\text { abnormalities }\end{array}$ & $\begin{array}{l}\text { Similar frequency of abnormalities in positive controls } \\
\text { and animals from uncontaminated areas }\end{array}$ \\
\hline
\end{tabular}


Table 3 Suggestions for future research

\begin{tabular}{ll}
\hline Analyses & Expectations \\
\hline Density-dependence & Greater frequency of abnormalities at high population density \\
Capture probability & $\begin{array}{l}\text { Minor abnormalities and smaller size should increase the probability of capture and hence the frequency } \\
\text { estimate }\end{array}$ \\
$\begin{array}{l}\text { Genome-wide sequencing to } \\
\text { quantify mutations }\end{array}$ & $\begin{array}{l}\text { Greater frequency of mutations in specimens from Fukushima than in control areas, increasing frequency } \\
\text { across generations due to mutation accumulation, and greater frequency in irradiated animals from the } \\
\text { laboratory compared to controls. }\end{array}$ \\
\hline
\end{tabular}

Fukushima would unequivocally demonstrate the association between irradiation and mutation accumulation, although we recognize that achieving such a goal would necessarily require a large financial investment, which has not generally been available for such studies in the past.

Finally, Hiyama et al. [10] emphasize that their study deals with the consequences of chronic rather than acute exposure to radiation, as will all studies of this phenomenon under field conditions. Again, this raises the question of why scientists working for the nuclear industry and in national and international laboratories have not already conducted extensive research on the consequences of such chronic radiation exposure. Unfortunately, funding for fundamental research in these areas in Japan, Europe and the US has never been large and has recently been scaled back [11]. Hopefully, the wide interest in such questions provoked by Hiyama et al. [8] will provide justification for greater investment in this research area of increasing societal relevance.

\section{Author details}

'Laboratoire d'Ecologie, Systématique et Evolution, CNRS UMR 8079, Université Paris-Sud, Bâtiment 362, F-91405, Orsay Cedex, France. ${ }^{2}$ Department of Biological Sciences, University of South Carolina, Columbia, SC 29208, USA.

Published: 30 August 2013

\section{References}

1. Møller AP, Mousseau TA: The effects of natural variation in background radioactivity on humans, animals and other organisms. Biol Rev 2013, 88:226-254.

2. Nadson GA, Philippov GS: Influence des rayons $x$ sur la sexualité et la formation des mutantes chez les champignons inferieurs (Mucorinées). $C$ R Soc Biol Fil 1925, 93:473-474.

3. Lubin J, Boice J Jr: Lung cancer risk from residential radon:meta-analysis of eight epidemiologic studies. J Natl Cancer Inst 1997, 89:49-57.

4. Lelieveld J, Kunkel D, Lawrence MG: Global risk of radioactive fallout after major nuclear reactor accidents. Atmos Chem Phys 2012, 12:4245-4258.

5. Møller AP, Mousseau TA: Biological consequences of Chernobyl: 20 years after the disaster. Trends Ecol Evol 2006, 21:200-207.

6. The Chernobyl Forum: 2003-2005: Chernobyl's Legacy: Health, Environmental and Socio-Economic Impacts. Vienna, Austria: International Atomic Energy Agency (IAEA); 2006.

7. Yablokov AV, Nesterenko VB, Nesterenko AV: Chernobyl: Consequences of the catastrophe for people and nature. Ann N Y Acad Sci 2009, 1181:1318-1326.

8. Hiyama A, Nohara C, Kinjo S, Taira W, Gima S, Tanahara A, Otaki JM: The biological impacts of the Fukushima nuclear accident on the pale grass blue butterfly. Nat Rep 2012, 2:570.
9. Møller AP, Swaddle JP: Asymmetry, Developmental Stability, and Evolution. Oxford: Oxford University Press; 1997.

10. Hiyama A, Nohara C, Taira W, Kinjo S, Iwata M, Otaki JM: The Fukushima nuclear accident and the pale grass blue butterfly: Evaluating biological effects of long-term low-dose exposures. BMC Evol Biol. 2013 13:168,

11. Mousseau TA, Møller AP: Perspectives on Chernobyl and Fukushima health effects: What can be learned from Eastern European research? J Health Pollution 2013, 3:2-6.

doi:10.1186/1741-7007-11-92

Cite this article as: Møller AP and Mousseau TA: Low-dose radiation, scientific scrutiny, and requirements for demonstrating effects. $B M C$ Biology 2013 11:92. 